\title{
Standard External Doppler Fetal Heart Tracings versus External Fetal Electrocardiogram in Very Preterm Gestation: A Pilot Study
}

\author{
Gary Fruhman, MD 1 \\ Erol Amon, MD, JD ${ }^{1}$ \\ Jeffrey A. Gavard, PhD² \\ Gilad A. Gross, MD ${ }^{1}$ \\ ${ }^{1}$ Division of Maternal Fetal Medicine, Department of Obstetrics, \\ Gynecology, and Women's Health, Saint Louis University School of \\ Medicine, Saint Louis, Missouri \\ 2 Division of Research, Department of Obstetrics, Gynecology, and \\ Women's Health, Saint Louis University School of Medicine, Saint \\ Louis, Missouri \\ ${ }^{3}$ SSM Health-Saint Mary's Hospital, Saint Louis, Missouri
}

Kristina McCormick, MD ${ }^{1}$

Judy Wilson-Griffin, $\mathrm{RN}^{3}$

\begin{abstract}
Address for correspondence Gary Fruhman, MD, Saint Louis University School of Medicine, 6420 Clayton Road, Suite 6520, Saint Louis, MO 63117 (e-mail: fruhman@slu.edu).
\end{abstract}

Am J Perinatol Rep 2016;6:e378-e383.

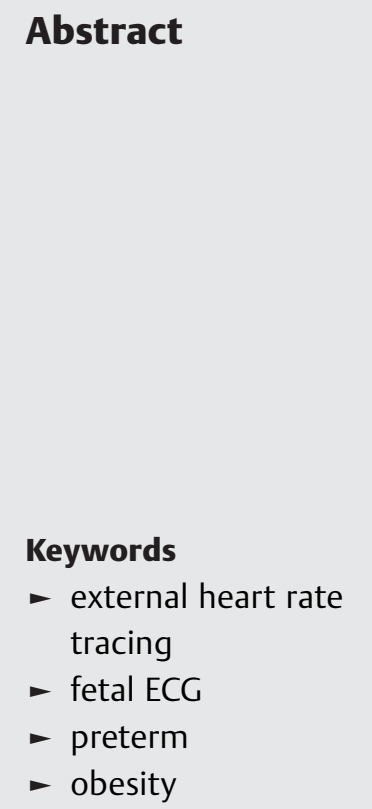

Introduction Very preterm babies can be difficult to monitor using standard external Doppler fetal heart tracings (eFHR). External fetal electrocardiogram (fECG) is a potential alternative.

Methods This was a prospective observational pilot study of hospitalized patients at 24 to 28 weeks' gestation. A total of 30 women were traced for up to 2 hours using eFHR followed by up to 2 hours using fECG. The percentage of time the fetal heart rate was traced during the 2-hour window for each modality was calculated. Differences of $\geq 60$, $\geq 80$, and $\geq 90 \%$ total time traced were compared between modalities using McNemar's test. Differences were also assessed for each method between nonobese (body mass index $[\mathrm{BMI}]<30 \mathrm{~kg} / \mathrm{m}^{2}$ ) and obese (BMI $\geq 30 \mathrm{~kg} / \mathrm{m}^{2}$ ) women using chi-square and Fisher's exact tests.

Results Superior performance was found with eFHR at $\geq 60 \%$ (93.3 vs. $46.7 \%$, $p<0.001), \geq 80 \%(80.0$ vs. $30.0 \%, p<0.001)$, and $\geq 90 \%(60.0$ vs. $23.3 \%$, $p<0.01)$ total time traced. There was a statistically significant finding favoring nonobese women at $\geq 80 \%$ total time traced using fECG (7.1 vs. $50.0 \%, p=0.017$ ).

Conclusion With current technology fECG performance in very preterm gestation was worse than conventional eFHR, although fECG may have a role in nonobese patients.
External Doppler fetal heart rate (eFHR) monitoring and tocodynamometry are routinely employed to evaluate fetal wellbeing. At times it can be very difficult to continuously trace the fetal heart rate, especially at very preterm gestation due to the size of the fetus coupled with fetal movement and maternal habitus. To successfully trace these signals, nursing staff may need to frequently reposition the patient or transducers. Staff quite often resorts to buttressing monitors with towels or manually applying the transducers for prolonged periods of time. In addition, patients are frequently placed in restrictive positions that can be a source of frustration and discomfort. Furthermore, the flat recumbent position that is often employed to capture a heart tracing potentially compromises uteroplacental gas exchange.

Transabdominal fetal electrocardiogram (fECG) acquisition and electrohysterography are alternative approaches to fetal received

May 24, 2016

accepted after revision

August 9, 2016
DOI http://dx.doi.org/

10.1055/s-0036-1592413. ISSN 2157-6998.
Copyright $\odot 2016$ by Thieme Medical Publishers, Inc., 333 Seventh Avenue, New York, NY 10001, USA. Tel: +1(212) 584-4662.
License terms

$\circledast(1) \Theta \circledast$ 
monitoring and it has been suggested in a prior study to be equivalent to external monitoring in the term population. ${ }^{1}$ In 2012, the U.S. Food and Drug Administration approved the use of the AN24 fetal ECG (Monica Healthcare, Nottingham,
United Kingdom) for fetal monitoring in labor at > 36 weeks' gestational age. ${ }^{2}$ Four electrodes are placed on the abdomen in a diamond-shaped pattern. One is placed above the pubic bone in the midline, one is placed just below the umbilicus,

Table 1 Demographic characteristics and medical/obstetrical history for 30 women

\begin{tabular}{|c|c|}
\hline Characteristics & Value \\
\hline Maternal age $(y)$ & $27.2 \pm 6.2$ \\
\hline \multicolumn{2}{|l|}{ Race } \\
\hline Caucasian & $16(53.3)$ \\
\hline African American & $14(46.7)$ \\
\hline \multicolumn{2}{|l|}{ Other } \\
\hline \multicolumn{2}{|l|}{ Marital status } \\
\hline Single & $12(40.0)$ \\
\hline Married & $14(46.7)$ \\
\hline Divorced & $4(13.3)$ \\
\hline Body mass index at admission $\left(\mathrm{kg} / \mathrm{m}^{2}\right)$ & $31.0 \pm 7.7$ \\
\hline \multicolumn{2}{|l|}{ Body mass index categories } \\
\hline Nonobese $(<30.0)$ & $16(53.3)$ \\
\hline Obese $(\geq 30.0)$ & $14(46.7)$ \\
\hline Gravidity & $2(1,3)$ \\
\hline Number of term births & $1(0,2)$ \\
\hline Number of preterm births & $0(0,0)$ \\
\hline Number of abortions & $0(0,1)$ \\
\hline Number of living children & $1(0,2)$ \\
\hline Gestational age at enrollment & $26.8(25.3,27.5)$ \\
\hline \multicolumn{2}{|l|}{ Placental location } \\
\hline Anterior & $13(43.3)$ \\
\hline Posterior & $14(46.7)$ \\
\hline Lateral & $3(10)$ \\
\hline \multicolumn{2}{|l|}{ Fetal orientation } \\
\hline Vertex & $25(83.3)$ \\
\hline Breech & $4(13.3)$ \\
\hline Transverse & $1(3.3)$ \\
\hline Preterm premature rupture of membranes & $5(16.7)$ \\
\hline Amniotic fluid deepest vertical pocket (cm) & $5.3(3.5,6.3)$ \\
\hline Estimated fetal weight $(\mathrm{g})$ & $909(637,1,012)$ \\
\hline Estimated fetal weight percentile & $44(31,61)$ \\
\hline \multicolumn{2}{|l|}{ Medical/obstetrical history } \\
\hline Chronic hypertension & $4(13.3)$ \\
\hline Diabetes (type 1 or type 2 ) & $3(10.0)$ \\
\hline Asthma & $3(10.0)$ \\
\hline Vaginal bleeding & $4(13.3)$ \\
\hline Preeclampsia & $1(3.3)$ \\
\hline Preterm labor & $4(13.3)$ \\
\hline Cervical insufficiency & $10(33.3)$ \\
\hline
\end{tabular}

Note: Data are shown as mean \pm standard deviation, median (interquartile range), or $\mathrm{n}$ (\%). 
and two are placed laterally, equidistant from the top and bottom electrodes. One electrode is placed lateral to the one on the right side and is used as a reference. ${ }^{3}$ The electrodes are then attached to the AN24 fetal ECG device. The goal of the multiple electrodes is to transmit the fetal heart tracing irrespective of fetal and/or maternal movement. Further studies have shown that unlike eFHR, fECG is not affected by maternal body mass index (BMI) and hence may be more successful in tracing the fetal heart rate in an obese population. ${ }^{4,5}$ Given these findings, we hypothesized that fECG may provide improved fetal monitoring in the very preterm population. Our study was designed to compare the success rates of fECG with those of eFHR in admitted antepartum gravidas between 24 and 28 weeks' gestational age.

\section{Methods}

This was a prospective, observational pilot study that took place at a single urban academic-affiliated communitybased hospital between October 2014 and January 2016. The study was approved by the Institutional Review Board of Saint Louis University School of Medicine. Admitted antepartum patients between 24 and 28 weeks' gestation were eligible to participate in the study. Gestational age was determined based on last menstrual period and confirmed with or re-dated by ultrasound; if this information was unknown then ultrasound dating was used. ${ }^{6}$ Exclusion criteria included multiple gestations, clinical instability, intrauterine fetal demise, and non-English speaking patients. Once a patient was deemed eligible for participation, she was approached and informed about the study. After informed consent was obtained, the patient was placed on the eFHR for up to 2 hours by the nursing staff, and was repositioned as necessary to maintain a continuous fetal heart tracing. The patient was then given a break for restroom use before being placed on the fECG for an additional 2 hours by one of the two authors (G. F. and J. W. G.). Per manufacturer instruction, before placement of the fECG electrodes, the abdomen was cleansed with soap and water and the skin was exfoliated to decrease impedance between the electrodes and the maternal abdomen. Upon completion of fECG monitoring, study participants were asked which method of fetal heart monitoring they preferred.

The percentage of time the fetal heart rate was traced during the 2-hour window for each modality was calculated as a percentage of the time. Continuous variables were compared using Wilcoxon signed rank tests. Differences of $\geq 60, \geq 80$, and $\geq 90 \%$ total time traced were compared between modalities using McNemar's test. Differences also were assessed for each method between nonobese (BMI $<30$ $\mathrm{kg} / \mathrm{m}^{2}$ ) and obese (BMI $\geq 30 \mathrm{~kg} / \mathrm{m}^{2}$ ) patients using Kolmogorov-Smirnov tests for continuous variables and chi-square and Fisher's exact tests for categorical variables. A $p$ value of $<0.05$ was used to denote statistical significance. All analyses were performed using SPSS version 21.0 for Windows (SPSS, Inc., Chicago, IL). As this was a pilot study, a sample size was not calculated. This trial is registered with clinicaltrials.gov (NCT02546011).

\section{Results}

Of the 36 patients recruited to participate, 30 patients were able to be analyzed. Of the six patients not included in the analysis, two were discharged before the study could be performed, two had a malfunctioning fECG, one required a higher level of obstetrical care before fECG monitoring, and one patient was determined to be 31 weeks' gestation following ultrasound evaluation. Demographic data and medical/obstetrical history of the 30 women are shown in -Table 1. - Table 2 demonstrates the results when the two modalities are compared. Standard eFHR monitoring yielded superior results at all time percentage points. These included: $\geq 60 \%$ time traced $(n=28$ [93.3\%] vs. $n=14$ [46.7\%], $p<0.001$ ), $\geq 80 \%$ time traced ( 80.0 vs. $30.0 \%$, $p<0.001)$, and $\geq 90 \%$ time traced $(60.0$ vs. $23.3 \%$, $p<0.01)$. The 30 patients were then divided into obese and nonobese groups ( - Table 3 ). A total of 14 women had a BMI $\geq 30 \mathrm{~kg} / \mathrm{m}^{2}$. There were no differences in demographics, medical/obstetrical histories or the percentage of time traced by eFHR between the obese and nonobese groups. fECG, however, was superior in the nonobese patient group. The median percentage of time the fECG was detected was $8 \%$ in the obese group compared with $83 \%$ in the nonobese patients $(p=0.048)$. In the obese group, an $80 \%$ tracing time was seen in only one patient $(7.1 \%)$ compared with eight patients $(50.0 \%)$ in the nonobese group $(p=0.017)$.

All patients preferred the comfort of fECG over eFHR. An additional finding of fECG monitoring was an increased amount of traced uterine activity from the electrohysterography lead, determined to be an artifact from patient movement. This finding was not systematically evaluated.

\section{Comment}

To our knowledge, this is the first study to compare eFHR to fECG for preterm gestation. We hypothesized that fECG would be better at recording the fetal heart tracing compared with eFHR. However, that was not the case for any of the cutoffs that we used. In 2008, Graatsma et $\mathrm{al}^{7}$ published a study of 150 women between 20 and 40 weeks' gestation who had 15 hours of fetal tracing using fECG. Out of the 150 recordings, 123 recordings (82\%) were considered to be of sufficient quality, which was defined as $\geq 60 \%$ time traced. In 2013, Hofmeyr et $\mathrm{al}^{8}$ published a study of 411 women between 20 and 24 weeks' gestation who used fECG to record the fetal heart tracing for at least 30 minutes. A total of 130 women (31.6\%) were excluded from analysis; 19 (4.6\%) were excluded because fECG did not detect the fetal heartbeat $>50 \%$ of the time. Of the 281 women analyzed, the mean signal loss as a percentage of recording time was $4 \%$ with a range of 0 to $46.3 \%$.

Quantifying what constitutes a fetal heart tracing of sufficient quality can be difficult and challenging to standardize. Many physicians order continuous monitoring for fetuses at preterm gestation at risk for adverse fetal events. Under these circumstances, the percentage of recorded and interpretable fetal heart tracing should be as high as possible. In our study, 
Table 2 Fetal heart tracing times and percentages for 30 women

\begin{tabular}{|l|l|l|l|}
\hline Characteristics & Standard tracing & Fetal electrocardiogram & $p$ Value \\
\hline Recording time (min) & $120(120,120)$ & $120(97,120)$ & $<0.005$ \\
\hline Time tracings were detected (min) & $112(95,118)$ & $59(3,108)$ & $<0.001$ \\
\hline Percentage of time tracings detected & $93(82,99)$ & $49(6,90)$ & $<0.001$ \\
\hline Tracings detected $\geq 60 \%$ & $28(93.3)$ & $14(46.7)$ & $<0.001$ \\
\hline Tracings detected $<60 \%$ & $2(6.7)$ & $16(53.3)$ & $<0.001$ \\
\hline Tracings detected $\geq 80 \%$ & $24(80.0)$ & $9(30.0)$ & \\
\hline Tracings detected $<80 \%$ & $6(20.0)$ & $21(70.0)$ & $<0.01$ \\
\hline Tracings detected $\geq 90 \%$ & $18(60.0)$ & $7(23.3)$ & $23(76.7)$ \\
\hline Tracings detected $<90 \%$ & $12(40.0)$ & & $<$ \\
\hline
\end{tabular}

Note: Data are shown as median (interquartile range) or $n(\%)$.

Table 3 Characteristics and fetal heart tracings of 14 obese and 16 nonobese women

\begin{tabular}{|c|c|c|c|}
\hline Characteristics & $\begin{array}{l}\text { Obese } \\
(N=14)\end{array}$ & $\begin{array}{l}\text { Nonobese } \\
(N=16)\end{array}$ & $p$ Value \\
\hline Maternal age $(y)$ & $28(22,35)$ & $28(20,31)$ & 0.395 \\
\hline \multicolumn{4}{|l|}{ Race } \\
\hline Caucasian & $7(50)$ & $9(56)$ & 0.732 \\
\hline African American & $7(50)$ & $7(44)$ & \\
\hline \multicolumn{4}{|l|}{ Other } \\
\hline \multicolumn{4}{|l|}{ Marital status } \\
\hline Single & $6(42.9)$ & $6(37.5)$ & 0.926 \\
\hline Married & $6(42.9)$ & $8(50.0)$ & \\
\hline Divorced & $2(14.3)$ & $2(12.5)$ & \\
\hline Body mass index at admission $\left(\mathrm{kg} / \mathrm{m}^{2}\right)$ & $37.4(34.2,42.2)$ & $25.9(21.3,27.9)$ & $<0.001$ \\
\hline Gravidity & $2(1,4)$ & $3(1,3)$ & 1 \\
\hline Number of term births & $1(0,2)$ & $1(0,2)$ & 0.995 \\
\hline Number of preterm births & $0(0,0)$ & $0(0,1)$ & 1 \\
\hline Number of abortions & $0(0,1)$ & $0(0,1)$ & 1 \\
\hline Number of living children & $1(0,2)$ & $1(0,2)$ & 0.751 \\
\hline Gestational age at enrollment & $26.8(25.4,27.4)$ & $26.5(25.0,27.6)$ & 0.971 \\
\hline \multicolumn{4}{|l|}{ Placental location } \\
\hline Anterior & $7(50)$ & $6(37.5)$ & 0.49 \\
\hline Posterior & $5(35.7)$ & $9(56.3)$ & \\
\hline Lateral & $2(14.3)$ & $1(6.3)$ & \\
\hline \multicolumn{4}{|l|}{ Fetal orientation } \\
\hline Vertex & $10(71.4)$ & $15(93.8)$ & 0.237 \\
\hline Breech & $3(21.4)$ & $1(6.3)$ & \\
\hline Transverse & $1(7.1)$ & $0(0.0)$ & \\
\hline Preterm premature rupture of membranes & $1(7.1)$ & $4(25.0)$ & 0.336 \\
\hline Amniotic fluid deepest vertical pocket (cm) & $5.3(3.6,6.3)$ & $5.3(3.7,6.2)$ & 0.936 \\
\hline Estimated fetal weight $(\mathrm{g})$ & $901(628,1004)$ & $942(610,1094)$ & 0.659 \\
\hline Estimated fetal weight percentile & $45(28,66)$ & $43(28,47)$ & 0.778 \\
\hline
\end{tabular}


e382 Standard eFHR versus fECG in Very Preterm Gestation: A Pilot Study Fruhman et al.

Table 3 (Continued)

\begin{tabular}{|c|c|c|c|}
\hline Characteristics & $\begin{array}{l}\text { Obese } \\
(N=14)\end{array}$ & $\begin{array}{l}\text { Nonobese } \\
(N=16)\end{array}$ & $p$ Value \\
\hline \multicolumn{4}{|l|}{ Medical/obstetrical history } \\
\hline Chronic hypertension & $3(21.4)$ & $1(6.3)$ & 0.315 \\
\hline Diabetes (type 1 or type 2 ) & $3(21.4)$ & $0(0.0)$ & 0.09 \\
\hline Asthma & $3(21.4)$ & $0(0.0)$ & 0.09 \\
\hline Vaginal bleeding & $1(7.1)$ & $3(18.8)$ & 0.602 \\
\hline Preeclampsia & $1(7.1)$ & $0(0.0)$ & 0.467 \\
\hline Preterm labor & $0(0.0)$ & $4(25.0)$ & 0.103 \\
\hline Cervical insufficiency & $5(35.7)$ & $5(31.3)$ & 1 \\
\hline \multicolumn{4}{|l|}{ External Doppler fetal heart tracing } \\
\hline Recording time (min) & $120(120,120)$ & $120(120,120)$ & 1 \\
\hline Time tracings were detected (min) & $106(83,120)$ & $112(99,116)$ & 0.851 \\
\hline Percentage of time tracings detected & $88(69,100)$ & $94(85,99)$ & 0.699 \\
\hline Tracings detected $\geq 60 \%$ & $13(92.9)$ & $15(93.8)$ & 1 \\
\hline Tracings detected $<60 \%$ & $1(7.1)$ & $1(6.3)$ & \\
\hline Tracings detected $\geq 80 \%$ & $10(71.4)$ & $14(87.5)$ & 0.378 \\
\hline Tracings detected $<80 \%$ & $4(28.6)$ & $2(12.5)$ & \\
\hline Tracings detected $\geq 90 \%$ & $7(50)$ & $11(68.8)$ & 0.296 \\
\hline Tracings detected $<90 \%$ & $7(50)$ & $5(31.3)$ & \\
\hline \multicolumn{4}{|l|}{ Fetal electrocardiogram } \\
\hline Recording time (min) & $119(35,120)$ & $120(120,120)$ & 0.244 \\
\hline Time tracings were detected (min) & $9(0,80)$ & $100(23,120)$ & 0.021 \\
\hline Percentage of time tracings detected & $8(0,69)$ & $83(19,100)$ & 0.048 \\
\hline Tracings detected $\geq 60 \%$ & $4(28.6)$ & $10(62.5)$ & 0.063 \\
\hline Tracings detected $<60 \%$ & $10(71.4)$ & $6(37.5)$ & \\
\hline Tracings detected $\geq 80 \%$ & $1(7.1)$ & $8(50.0)$ & 0.017 \\
\hline Tracings detected $<80 \%$ & $13(92.9)$ & $8(50.0)$ & \\
\hline Tracings detected $\geq 90 \%$ & $1(7.1)$ & $6(37.5)$ & 0.086 \\
\hline Tracings detected $<90 \%$ & $13(92.9)$ & $10(62.5)$ & \\
\hline
\end{tabular}

Note: Data are shown as median (interquartile range) or $\mathrm{n}(\%)$.

we used three different percentages as cutoffs to define tracings of sufficient quality, and eFHR uniformly performed better than fECG.

The maternal BMI has been previously shown to not interfere with fECG tracings in term gestations. ${ }^{4,5}$ This finding was not consistent in our study when the modality was applied to preterm gestation. fECG was more likely to provide tracings of sufficient quality in patients with a BMI $<30 \mathrm{~kg} /$ $\mathrm{m}^{2}$ for all three cutoff points, but did not perform as well as eFHR.

Strengths of this study include its prospective design, and that each patient served as her own control. There are limitations that warrant discussion. Because this is a pilot study, the sample size is small. eFHR and fECG tracings were performed sequentially, not contemporaneously, which is technically not feasible. In addition, we initially started the study with patients receiving continuous fetal monitoring due to concern over fetal wellbeing. After 10 patients were recruited, we decided to perform the study on patients who did not require continuous fetal monitoring because some fECG tracings were not of sufficient quality to provide reassurance of fetal status. These patients were not on the fECG for a full 2 hours. Furthermore, there is a significant learning curve to applying and using the fECG. The patient's skin requires exfoliation with a certain amount of pressure before placing the electrodes to reduce skin impedance. Suboptimal exfoliation will result in increased noise and may hinder the quality of tracings.

In conclusion, eFHR performed better than fECG in recording fetal heart tracings in singleton gestations between 24 and 28 weeks. However, $100 \%$ of patients preferred the comfort of fECG over eFHR and thus fECG may have clinical utility in preterm gravidas with a $\mathrm{BMI}<30 \mathrm{~kg} / \mathrm{m}^{2}$. There is a newer version of the AN24 monitor (Monica Healthcare Ltd., 
Nottingham, United Kingdom), which was designed to reduce noise from the maternal heart rate as well as more accurately record uterine activity. ${ }^{9}$ Further studies are needed to optimize this technology in the preterm population.

\section{Conflict of Interest}

The authors report no conflict of interest.

\section{Acknowledgment}

The authors would like to thank Monica Healthcare Ltd., Nottingham, United Kingdom (available at: http://www. monicahealthcare.com) for providing the electrodes for this study.

\section{References}

1 Cohen WR, Ommani S, Hassan S, et al. Accuracy and reliability of fetal heart rate monitoring using maternal abdominal surface electrodes. Acta Obstet Gynecol Scand 2012;91(11): 1306-1313
2 Food and Drug Administration. Monica Healthcare K112390 510 (K) Summary. Monica AN24. Available at: http://www.accessdata. fda.gov/cdrh_docs/pdf11/K112390.pdf. Accessed April 18, 2016

3 Monica Healthcare. Monica AN24 with IF24. Available at: http:// www.monicahealthcare.com/products/labour-and-delivery/ monica-an24-with-if24. Accessed May 23, 2016

4 Graatsma EM, Miller J, Mulder EJ, Harman C, Baschat AA, Visser GH. Maternal body mass index does not affect performance of fetal electrocardiography. Am J Perinatol 2010;27(7):573-577

5 Cohen WR, Hayes-Gill B. Influence of maternal body mass index on accuracy and reliability of external fetal monitoring techniques. Acta Obstet Gynecol Scand 2014;93(6):590-595

6 Committee opinion no 611: method for estimating due date. Obstet Gynecol 2014;124(4):863-866

7 Graatsma EM, Jacod BC, van Egmond LA, Mulder EJ, Visser GH. Fetal electrocardiography: feasibility of long-term fetal heart rate recordings. BJOG 2009;116(2):334-337, discussion 337338

8 Hofmeyr F, Groenewald CA, Nel DG, et al; PASS Network. Fetal heart rate patterns at 20 to 24 weeks gestation as recorded by fetal electrocardiography. J Matern Fetal Neonatal Med 2014;27(7): 714-718

9 Monica Healthcare. Novii wireless patch system. Available at: http:// www.monicahealthcare.com/products/labour-and-delivery/monicanovii-wireless-patch-system. Accessed May 23, 2016 